\title{
Gamma Irradiation of Hexafluorobenzene
}

\author{
R. E. Florin, L. A. Wall, and D. W. Brown
}

(March 27, 1960)

\begin{abstract}
Mixtures of hexafluorobenzene and benzene were irradiated in liquid phase by means of a $\mathrm{Co}^{60}$ gamma source at $20^{\circ}$ and at $218^{\circ} \mathrm{C}$. Perfluoroheptane and various binary mixtures involving perfluoroheptane, hexafluorobenzene, benzene, and cyclohexane were also irradiated at $20^{\circ} \mathrm{C}$. Hexafluorobenzene resembled benzene very closely in its behavior upon radiolysis. Generally the fluorocarbon-hydrocarbon mixtures evolved much more $\mathrm{SiF}_{4}$ (indicating the formation of $\mathrm{HF}$, which reacts with the glass vessel) than the pure fluorocarbon components. The polymer from hexafluorobenzene-benzene mixtures was probably rich in cyclohexadiene and cyclohexene units, resembling that from pure benzene, and its composition ratio exhibited a strong "alternating" tendency. The results are discussed in terms of free-radical and excited-state mechanisms. At $218^{\circ} \mathrm{C}$ hexafluorobenzene and also its mixtures with benzene showed qualitative differences from their behavior at $20^{\circ} \mathrm{C}$, although the $G$ values for $\mathrm{SiF}_{4}$ and polymer remained moderate.
\end{abstract}

\section{Introduction}

Fully fluorinated aromatic compounds have only recently become accessible. Because of their combination of $\mathrm{C}-\mathrm{F}$ bonds and aromatic resonance structure they have attracted interest as possible heat-resistant materials. It has been observed that certain polyphenyls $\left(\mathrm{C}_{6} \mathrm{~F}_{4}\right)_{x}$ are stable at high temperatures [1] ${ }^{2}$ and that the mass spectrum of these compounds shows relatively little fragmentation under electron impact [2]. The latter observation is reminiscent of benzene itself, and contrasts strongly with the extensive fragmentation of saturated fluorocarbons in the mass spectrometer $[3,4]$.

Since electrons are an important intermediate in the action of ionizing radiation, it can be expected that hexafluorobenzene derivatives, like their hydrocarbon analogs, will be relatively resistant to radiation, and may surpass them under some combinations of high temperature and radiation. Any improvement in materials for use under such conditions would be desirable.

The radiation chemistry of fluorocarbons has been studied very little until very recently, except for a few polymers and monomers [5 to 14]. Halogen compounds, including a few monofluoro derivatives, have been investigated and generally have been found to exhibit a very high sensitivity to radiation [15]. Benzene has been studied very extensively, both because of its low sensitivity and the possibility that it can exhibit a "protective" effect in mixtures. Likewise, a few higher aromatic hydrocarbons have been studied $[16$ to 18]. In radiation chemical studies in general, atom and free-radical mechanisms have been fairly well accepted [19], though seldom unequivocally proven. Besides the great wealth of data on hydrocarbon radical reactions [20], there have recently been a number of studies on reactions of aliphatic fluorocarbon radical [21 to 29].

The present situation is that fluorocarbons seem

1 This work was sponsored by the Aeronautical Research Laboratory, Wright Air Development Center, U.S. Air Force.

2 Figures in brackets indicate the literature references at the end of this paper. more resistant than hydrocarbons to heat, and also aromatic compounds more resistant than aliphatic. Under ionizing radiation, aliphatic hydrocarbons give off relatively large amounts of hydrogen; aromatic hydrocarbons lose very little hydrogen, but form polymers in moderate yield. Aliphatic fluorocarbons suffer breaks in the carbon chain and lose slight to moderate amounts of fluorine in ionic form 17 to 9$]$. The aromatic hydrocarbons biphenyl and terphenyl are resistant enough to radiation at high temperatures to be of some interest as reactor coolants [18]. The order of magnitude of the radiation yield, $G$, in molecules per 100 ev absorbed, is indicated in table 1 for the several processes. In this paper, we report some observations on the irradiation of $\mathrm{C}_{6} \mathrm{~F}_{6}, \mathrm{C}_{7} \mathrm{~F}_{16}$, and their mixtures with other materials.

TABLE 1. Radiation yields for several processes

\begin{tabular}{l|r|r|r}
\hline \hline \multirow{2}{*}{ Process } & \multicolumn{3}{|c}{$G$ value } \\
\cline { 2 - 4 } & $C_{n} \mathrm{H}_{2 n+2}$ & $\mathrm{C}_{6} \mathrm{H}_{6}$ & $\mathrm{C}_{n} \mathrm{~F}_{2 n+2}$ \\
\hline $\mathrm{C}-\mathrm{C}$ scission & $<1$ & 0.02 & 1.7 \\
$\mathrm{H}_{2}$ or $\mathrm{F}_{2}$ & 5 & .04 & 0.1 \\
\hline Polymer or crosslinks & 5 & 1 & 0 \\
\hline
\end{tabular}

\section{Experimental Procedure}

In general, samples were prepared on a vacuum line and irradiated to doses of about 100 to 300 megaroentgens $(\mathrm{Mr})$. Products volatile at $-80^{\circ}$ and $25^{\circ} \mathrm{C}$ were analyzed by mass spectrometer. Nonvolatile residues were isolated by distillation of the liquid and characterized by infrared spectra and elemental analysis. The hexafluorobenzene used was from a specially purified center cut of material synthesized in our laboratory [30] and subjected to repeated fractional freezing. Its constants were $\mathrm{bp}=80.5^{\circ} \mathrm{C} / 759 \mathrm{~mm}, n_{23}^{D}=1.3781$. The benzene used was the commercial product (c.p.), not further purified. The perfluoroheptane used was the product of Minnesota Mining \& Manufacturing Co. and was used as received. The cyclohexane used was an NBS standard sample. 
For the irradiations at room temperature, the liquids were dried several weeks over $\mathrm{P}_{2} \mathrm{O}_{5}$ in breakseal tubes and distilled on the vacuum line into weighing bulbs of $30-\mathrm{ml}$ capacity. These bulbs were fitted with standard taper joints and Hoke bellows valves connected via copper or Kovar glass seals. Samples were made up by distilling in vacuo into irradiation vessels of several kinds, then degassing, cooling with liquid nitrogen, opening for about 1 minute to a measured pressure of a few centimeters of argon, and sealing or closing off. Weights of components of the mixture, obtained by difference, were checked against the total weight of the radiation vessel. Discrepancies of a few milligrams were common, probably because of absorption of the volatile liquids in stopcock grease.

The radiation vessels for use at $218^{\circ} \mathrm{C}$ were $3-\mathrm{mm}$ thick-walled glass tubes. At room temperature nickel capsules of about $10-$ to $15-\mathrm{ml}$ capacity were used. They were silver-soldered to $1.5-\mathrm{mm} \times 40-\mathrm{mm}$ nickel tubes and then through 4.7-mm o.d. Kovar seals to long $3-\mathrm{mm}$ o.d. Pyrex end sections which were designed for opening into the mass spectrometer inlet system. In one irradiation experiment under a high pressure of hydrogen, a third type of radiation vessel was used, consisting of a Monel bomb, 12-mm o.d. x 6-mm i.d. x $300 \mathrm{~mm}$ in length, closed by a Hoke bellows valve. The simple capillary tube had the advantages of strength and small size but had a large potentially reactive wall surface and also could not be opened for analysis without some exposure to air. The composite capsules were mostly corrosion resistant, vacuumtight, and easily fitted to the mass spectrometer but were very fragile after use. The existence of a partial internal glass surface had some advantages as well as drawbacks. Any HF formed was converted to the easily measured $\mathrm{SiF}_{4}$, while any reactive fluorocarbon intermediates of short life probably underwent further reaction in the liquid system before they could diffuse to the glass surface. It was noticed that corrosion was especially severe in the special graded glass of the Kovar seal. The Monel bomb vessel had the advantage of strength and all-metal construction but probably was subject to slow leaks over long periods. It is uncertain whether it would have remained tight with the valve exposed to high temperatures.

The sample tubes to be irradiated were placed in a can and lowered into the uniform central region of a 2,000-curie cobalt-60 source consisting of upright rods arranged in a circle and shielded by water. Heat, when needed, was provided within the can by a thermostat furnace capable of reaching $500^{\circ} \mathrm{C}$. Electrical leads were carried through a pipe leading to the surface of the water. The exposure dose rate was determined by the ferrous sulfate dosimeter using $G=15.5$, and by a time correction for decay of the cobalt. The dose rate was $0.576 \mathrm{Mr} / \mathrm{hr}$ on December 11, 1956. The variations with geometry (mainly vertical extension) and container wall shielding were significant only for the Monel bomb containers. The absorbed dose was calculated with the aid of best values for the elements, derived from ref [31]. Typical factors in ev $\mathrm{g}^{-1} \mathrm{Mr}^{-1} \times 10^{-20}$ were: $\mathrm{C}_{\mathrm{n}} \mathrm{H}_{2 \mathrm{n}}, 0.623 ; \mathrm{C}_{6} \mathrm{H}_{6}, 0.589 ; \mathrm{C}_{\mathrm{n}} \mathrm{F}_{2 \mathrm{n}}, 0.526$; and $\mathrm{C}_{6} \mathrm{~F}_{6}, 0.530$.

After irradiation, which required several weeks, the samples were brought to the mass spectrometer whenever the design of the vessel was appropriate, and mass spectra taken with contents at $-80^{\circ}$ and $+25^{\circ} \mathrm{C}$. Where the container was not adapted for this, the contents were first transferred on an auxiliary vacuum line. Many of the Kovar-seal containers in which hydrocarbon-fluorocarbon mixtures were exposed to high doses were broken during irradiation or subsequent handling because of corrosion at the glass-metal seals. To calculate the mass spectrometer results for gaseous products, reliance was placed upon the argon introduced as an internal standard. For liquid products, the examination at $25^{\circ} \mathrm{C}$ vielded only relative values, distorted by fractionation effects. The opened tubes were emptied by suction, and the liquid content was frozen and sublimed at reduced pressure to isolate the nonvolatile residue. The empty tubes were rinsed with benzene repeatedly, yielding small additional amounts of residue. The residues were analyzed ${ }^{3}$ for $\mathrm{C}, \mathrm{H}$, and $\mathrm{F}$, and infrared spectra ${ }^{4}$ were also taken in films and Nujol mulls.

In the mass spectrometric procedure, bulbs containing a large liquid sample were connected to the inlet system of the mass spectrometer before breaking the seal. Analyses of volatiles were then made with the sample bulb first cooled to $-80^{\circ} \mathrm{C}$ and then warmed to $25^{\circ} \mathrm{C}$. The analysis of material volatile at $-80^{\circ} \mathrm{C}$ should give a reasonably accurate estimate of gaseous products for all samples in which the liquid was completely frozen at that temperature. This includes all samples containing hexafluorobenzene, benzene, and cyclohexane only. However, perfluoroheptane, although the reported freezing point is $-55^{\circ}$, is often still liquid at $-80^{\circ} \mathrm{C}$ and therefore can hold large quantities of gases in solution. For samples containing perfluoroheptane, therefore, the mass spectrometric analyses at $-80^{\circ} \mathrm{C}$ may seriously underestimate the yields of gases. This error will be greatest for the samples rich in perfluoroheptane and for the higher boiling gases such as $\mathrm{CF}_{4}\left(\mathrm{bp}-128^{\circ} \mathrm{C}\right), \mathrm{SiF}_{4}\left(\mathrm{subl}-95^{\circ} \mathrm{C}\right)$, $\mathrm{C}_{2} \mathrm{~F}_{6}$ (bp $-76.3^{\circ} \mathrm{C}$ ), and $\mathrm{CF}_{3} \mathrm{H}\left(\mathrm{bp}-84.4^{\circ} \mathrm{C}\right)$.

For similar reasons, the volatiles at $25^{\circ} \mathrm{C}$ have merely qualitative interest. Products less volatile than the starting material will appear in greatly reduced concentration. The results will be especially uncertain for products of intermediate volatility, which are depleted in supply because of the previous analysis at $-80^{\circ} \mathrm{C}$, but favored by high relative volatility at $25^{\circ} \mathrm{C}$.

Polymeric residues in irradiated samples were analyzed by combustion methods. In many instances, the sum of $\mathrm{C}, \mathrm{H}$, and $\mathrm{F}$ is low by several percent. The deficit may be attributed either to poor accuracy of fluorine analyses or to oxygen ab. sorbed during the period between opening of samples and analysis. The polymeric product from irradi-

\footnotetext{
${ }^{3}$ Combustion analyses were by E. R. Deardorff, NBS.
${ }^{4}$ Spectra were obtained by John J. Comeford and W. J. Pummer, NBS
} 
ated benzene is highly reactive with oxygen [16], and the related material from fluorocarbons could react not only with oxygen but with moisture as well. These reactions should have been minimized in the present work by the fact that the longest storage of samples was in the crystalline or glassy form. It will therefore be assumed in calculations that the total deficit is due to low fluorine analyses.

A nearly self-consistent account can be given of the composition of $\mathrm{C}_{6} \mathrm{~F}_{6}-\mathrm{C}_{6} \mathrm{H}_{6}$ residues by postulating combination of molecules and elimination of HF. The calculations will be deferred until the discussion of these mixtures. In most other mixtures, the polymer analysis is consistent with several possibilities, but extremes can be calculated.

The metallic interior surfaces of the containers appeared unchanged after irradiation. A monomolecular layer of metal fluoride may possibly have been present, but this could not contribute important errors at the doses used in this work.

All of the systems containing some fluorocarbon and some glass produced $\mathrm{SiF}_{4}$.

In the capillary tubes containing $\mathrm{C}_{6} \mathrm{~F}_{6}$ at $218^{\circ} \mathrm{C}$, this product may have been formed by direct reaction of excited molecules with the wall. In the composite metal bulb reactors, the long diffusion path makes it very unlikely that short-lived intermediates of any kind could reach the glass parts in significant quantity. Among possible agents attacking the glass are $\mathrm{F}_{2}$, HF, and perhaps especially reactive fluorocarbon molecules.

Radicals or fluorocarbon molecules attacking glass should produce $\mathrm{CO}$ or $\mathrm{CO}_{2}$, as well as $\mathrm{SiF}_{4}$ :

$$
4 \mathrm{CF}_{3} \cdot+3 \mathrm{SiO}_{2} \longrightarrow 3 \mathrm{SiF}_{4}+2 \mathrm{CO}+2 \mathrm{CO}_{2} .
$$

The steps would involve gradual replacement of $\mathrm{O}$ by $\mathrm{F}$ in the glass lattice until a volatile $\mathrm{SiF}_{4}$ molecule is produced:

$$
-\mathrm{C}-\mathrm{F}+-\mathrm{Si}-\mathrm{O} \rightarrow-\mathrm{C}-\mathrm{O}-+\underset{\mid}{\mid} \mathrm{Si}-\mathrm{F} .
$$

Reactions not producing oxides of carbon are also possible:

$$
\mathrm{C}_{2} \mathrm{~F}_{5} \cdot+\underset{\mid}{\mathrm{Si}-\mathrm{O} \longrightarrow} \longrightarrow \mathrm{C}_{2} \mathrm{~F}_{4}+\underset{\mid}{\mid} \mathrm{Si}-\mathrm{F}+-\mathrm{O}-
$$

The reaction of $\mathrm{F}_{2}$ with glass would apparently produce oxygen as a byproduct:

$$
2 \mathrm{~F}_{2}+\mathrm{SiO}_{2} \longrightarrow \mathrm{SiF}_{4}+\mathrm{O}_{2} .
$$

This oxygen could react with radicals to form oxides of carbon or oxygenated fluorocarbon compounds. Despite the known slowness of the glass-fluorine reaction, it appears likely that it should occur in appreciable amounts over the long radiation times. Even in view of the uncertainties implied by the above reactions, it seems reasonable to consider each $\mathrm{SiF}_{4}$ molecule as derived from $4 \mathrm{HF}$ in mixtures with hydrocarbons, and from $2 \mathrm{~F}_{2}$ in pure fluoro- carbon systems, unless equivalent amounts of $\mathrm{CO}$ or $\mathrm{CO}_{2}$ are observed. The $\mathrm{CO}$ and $\mathrm{CO}_{2}$ were usually observed only in very small amounts relative to $\mathrm{SiF}_{4}$. The reaction involving $\mathrm{HF}$ should produce water as a by-product:

$$
4 \mathrm{HF}+\mathrm{SiO}_{2} \longrightarrow 2 \mathrm{H}_{2} \mathrm{O}+\mathrm{SiF}_{4} .
$$

Conversion of HF to $\mathrm{SiF}_{4}$ is presumed to be nearly complete, although some fixation in the form of alkali fluosilicates is conceivable. The above reactions show that the later stages of the irradiation may be complicated by gradually increasing amounts of oxygen and water.

Most of the materials were irradiated only at room temperature, but hexafluorobenzene and the $\mathrm{C}_{6} \mathrm{~F}_{6}-\mathrm{C}_{6} \mathrm{H}_{6}$ mixtures were irradiated at both $20^{\circ}$ and $218^{\circ} \mathrm{C}$.

\section{Results and Discussion}

\subsection{Hexafluorobenzene}

From pure hexafluorobenzene the observed products were a nonvolatile residue (the so-called "polymer," table 2) and $\mathrm{SiF}_{4}$ (tables 3 and 4 ) with a little $\mathrm{CO}$ and $\mathrm{CO}_{2}$, which may have been derived from fluorine atoms or molecules or unstable fluorocarbon intermediates. At $20^{\circ}$ the release of fluorine was almost negligible, $G\left(\mathrm{SiF}_{4}\right)=0.01$, but at $218^{\circ}$ it became 0.21 molecules $/ 100 \mathrm{ev}$. The yield of polymer was about the same at both temperatures within the large experimental error at $218^{\circ}$ and was about twice that from benzene. $G$ (polymer) $=2.01$ at $20^{\circ}$, $1.3 \pm 0.5$ at $218^{\circ}$. The character of the polymer changed greatly with temperature, being a light yellow, low-melting $\left(<100^{\circ}\right)$ glass at $20^{\circ}$, and a

\begin{tabular}{|c|c|c|c|}
\hline $\mathrm{C}_{6} \mathrm{~F}_{6}$ in feed, mole fraction & 1.00 & 0.667 & 0.114 \\
\hline $\begin{array}{l}\mathrm{C}_{6} \mathrm{~F}_{6} \text { in polymer, mole fraction } \\
\text { Polymer weight } \\
\% \% \mathrm{C} \\
\% \mathrm{H} \\
\% \mathrm{~F} \text { - } \\
\text { Base moles } \\
\mathrm{HF} \text { moles lost per mole }\end{array}$ & $\begin{array}{l}0.922 \\
.7051 \\
40.2 \\
\text { b } 0.3 \\
55 . \\
0.00394\end{array}$ & $\begin{array}{l}0.527 \\
.6822 \\
55.3 \\
2 . \\
38.4 \\
.00524 \\
.230\end{array}$ & $\begin{array}{l}0.422 \\
.860 \\
61.2 \\
2.7 \\
31.2 \\
.00731 \\
.296\end{array}$ \\
\hline
\end{tabular}
nearly black finely granular precipitate at $218^{\circ}$. The elemental analysis of the $20^{\circ}$ polymer was near

TABLE 2. Polymer from irradiated hexafluorobenzene and benzene at $20^{\circ} \mathrm{C}$ a

TABLE 3. Radiation yields from hexafluorobenzene and benzene at $20^{\circ} \mathrm{C}$ s

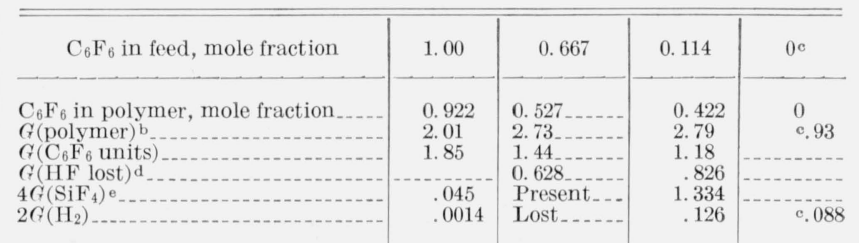

a Exposure dose $275 \mathrm{Mr}$; dose factors for $\mathrm{C}_{6} \mathrm{H}_{6}, 0.589 \times 10^{20} \mathrm{ev} / \mathrm{g}-\mathrm{Mr}$; for $\mathrm{C}_{6} \mathrm{~F}_{6}$, $0.530 \times 10^{20} \mathrm{ev} / \mathrm{g}-\mathrm{Mr}$.

b $\mathrm{C}_{6} \mathrm{H}_{6}$ and $\mathrm{C}_{6} \mathrm{~F}_{6}$ units,

c From Gordon et al, ref. [17].

d From polymer analysis.

e From gas analysis. 
TABLE 4. Radiation yields from hexafluorobenzene and benzene at $218^{\circ} \mathrm{C}$ s

\begin{tabular}{|c|c|c|c|}
\hline $\mathrm{C}_{6} \mathrm{~F}_{6}$ mole fraction & 1.00 & 0.256 & 0 \\
\hline $\begin{array}{l}4 G\left(\mathrm{SiF}_{4}\right) \\
G(\mathrm{CO}) \\
G\left(\mathrm{CO}_{2}\right) \\
G\left(\mathrm{H}_{2}\right) \\
G\left(\mathrm{C}_{2} \mathrm{H}_{2}\right) \\
G(\text { polymer })^{\mathrm{b}}\end{array}$ & $\begin{array}{l}0.84 \\
.054 \\
.022 \\
0 \\
0 \\
1.3 \pm 0.5\end{array}$ & $\begin{array}{r}0.105 \\
.0063 \\
.0048 \\
.0075 \\
.0048 \\
1 \pm 0.5\end{array}$ & $\begin{array}{l}0 \\
0 \\
0 \\
.0022 \\
.017 \\
1.3\end{array}$ \\
\hline
\end{tabular}

that of the parent compound (table 2). The deficit, $100-\mathrm{C}-\mathrm{F}-\mathrm{H}$, and $\mathrm{H}$ content may represent contaminations in handling, difficulties of quantitative fluorine determination, or in the case of the deficit possibly oxygen absorption during storage $[16,17]$. The quantity of the $218^{\circ} \mathrm{C}$ polymer was not sufficient for analysis.

Infrared spectra of the polymer and a synthetic perfluoropolyphenyl are compared in figure 1. Both have strong peaks at 6.6 and at $10.15 \mu$, but the radiation polymer has a broader absorption generally and numerous additional peaks at 5.7, 7.5, 8.8, $12.8,13.3$, and $13.7 \mu$. Most of the absorption bands are consistent with a $\mathrm{C}-\mathrm{F}$ bond adjacent to either an aromatic or an olefinic carbon atom. The infrared absorption offers no reliable basis for a distinction.

There appear to be no small fluorocarbon molecules analogous to the $\mathrm{C}_{2} \mathrm{H}_{2}$ and $\mathrm{CH}_{4}$ found with benzene. The similarity of $\mathrm{C}_{6} \mathrm{~F}_{6}$ to $\mathrm{C}_{6} \mathrm{H}_{6}$ was striking-very low yields of volatile products, and a moderate yield of polymer; $G$ (polymer) $=2.01$ for $\mathrm{C}_{6} \mathrm{~F}_{6}$, and 0.93 for $\mathrm{C}_{6} \dot{\mathrm{H}}_{6}$.

It is recognized that nearly the total effect of ionizing radiation on organic matter is due to the secondary electrons. Their first effect is to form positive ions which can be important intermediates in the gas phase [32] but are more likely to recapture electrons in liquid phase and form neutral radicals and atoms. Although the number of excited molecules (singlet and triplet) may considerably exceed the number of unexcited radicals formed [19], it is often possible to restrict attention to atoms and radicals as the effective chemical intermediates. Feng $[13,14]$ has briefly considered ionic intermediates, pointing out that atom formation is
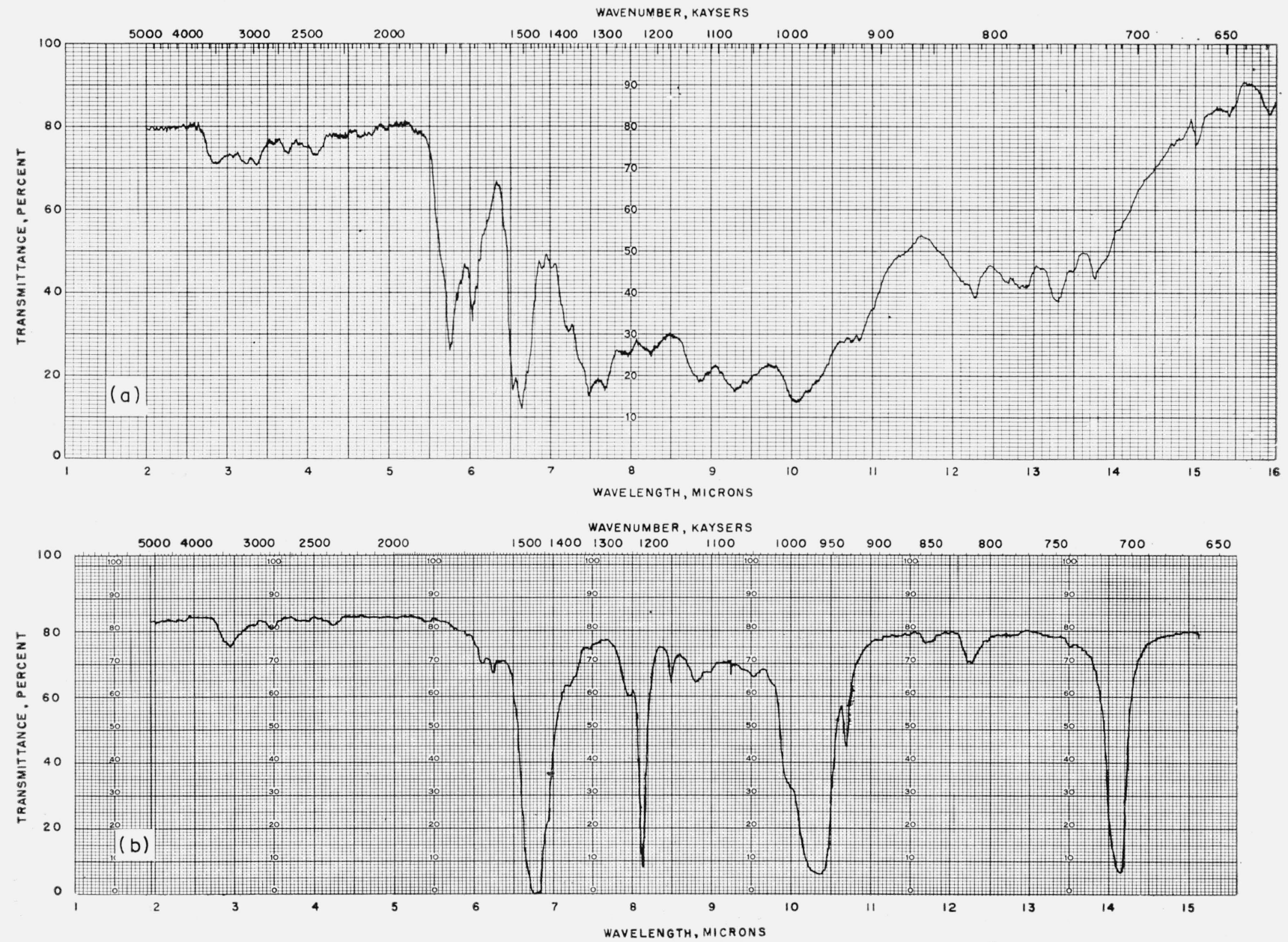

FIGURE 1. Infrared absorption spectra of hexafluorobenzene radiation polymer and of perfluoropolyphenyl. a. $\mathrm{C}_{6} \mathrm{~F}_{6}$ radiation polymer. b. I- $\left(\mathrm{C}_{6} \mathrm{~F}_{4}\right)_{11}-\mathrm{I}$. 
energetically less favorable for carbon-fluorine than for other carbon-halogen bonds, and other investigators $[16,17]$ have introduced excited states in the discussion of the radiolysis of benzene.

The radiolysis of hexafluorobenzene offers few novelties beyond its hydrocarbon analog; both the free-radical mechanisms and excited-state mechanisms $\mid 16,17]$ seem admissible with little choice. The outlines of a free-radical mechanism, following Burton's [16] treatment of $\mathrm{C}_{6} \mathrm{H}_{6}$, would be

$$
\begin{gathered}
\mathrm{C}_{6} \mathrm{~F}_{6} \longrightarrow \mathrm{C}_{6} \mathrm{~F}_{5} \cdot+\mathrm{F} \cdot, \\
\mathrm{C}_{6} \mathrm{~F}_{6}+\mathrm{F} \cdot \longrightarrow \mathrm{C}_{6} \mathrm{~F}_{7} \cdot \\
\mathrm{R} \cdot+\mathrm{C}_{6} \mathrm{~F}_{6} \longrightarrow \mathrm{RC}_{6} \mathrm{~F}_{6} \cdot\left(\mathrm{R} \cdot=\mathrm{C}_{6} \mathrm{~F}_{5}, \mathrm{C}_{6} \mathrm{~F}_{7} \cdot \mathrm{C}_{6} \mathrm{~F}_{6} \mathrm{C}_{6} \mathrm{~F}_{5} \cdot\right), \\
\mathrm{R} \cdot+\mathrm{R} \cdot \stackrel{\mathrm{RR},}{\longrightarrow}, \\
\mathrm{R} \cdot+\mathrm{F} \cdot \longrightarrow \mathrm{RF} .
\end{gathered}
$$

Reactions (7) and (8), by analogy with the hydrogen atom-benzene reaction, probably have an activation energy of several kilocalories at most. The activation energy of reaction (8) would be reduced for $\mathrm{C}_{6} \mathrm{~F}_{6}$ in an excited state. The low yield $(G=2.01)$ does not require a chain reaction; however, the structure of the polymer (less volatile than biphenyl, melting below $100^{\circ}$ to a moderately viscous liquid) requires a few addition steps like reaction (8). No abstraction reaction has been introduced:

$$
\mathrm{R} \cdot+\mathrm{C}_{6} \mathrm{~F}_{6} \rightarrow \mathrm{RF}+\mathrm{C}_{6} \mathrm{~F}_{5} .
$$

External evidence against reaction (11) is twofold. In the first place, in hydrocarbon analogs reaction (11) is slower than (8) at room temperature and below, e.g., addition dominates in the photochlorination of benzene [20] and the reaction of $\mathrm{H}$ atoms with frozen benzene [33]. The ratio, addition/ abstraction, may be about 7.5 in radiolysis of mixtures of $\mathrm{C}_{6} \mathrm{H}_{6}$ and $\mathrm{C}_{6} \mathrm{D}_{6}$ [34].

Observation of $\mathrm{C}_{6} \mathrm{H}_{5} \mathrm{CF}_{3}$ in the radiolysis of mixtures of $\mathrm{CF}_{4}$ and $\mathrm{C}_{6} \mathrm{H}_{6}[13,14]$ may require abstraction from $\mathrm{C}_{6} \mathrm{H}_{6}$ if the mechanism is of the free-radical type. Abstraction of $\mathrm{H}$ from $\mathrm{C}_{6} \mathrm{H}_{6}$ is postulated in the radiolysis of dilute aqueous benzene, the ultimate products being $\mathrm{C}_{6} \mathrm{H}_{5} \mathrm{OH}$ and $\left(\mathrm{C}_{6} \mathrm{H}_{5}\right)_{2}$ [35]. In both these instances, the attacking radical is highly electronegative.

The second evidence against reaction (11) is that fluorine atoms are not readily abstracted from perfluoroparaffins by ordinary atoms and radicals such as $\mathrm{H}$ [36], $\mathrm{CH}_{3}$ [37], $\mathrm{CF}_{3}[28]$, and $\mathrm{C}_{2} \mathrm{~F}_{5}[27,29]$. Presumably, the fiuorine atoms of aromatic fluorocarbons are likewise resistant. For the abstraction reaction

$$
\mathrm{H} \cdot+\mathrm{CF}_{4} \longrightarrow \mathrm{HF}+\mathrm{CF}_{3} \text {. }
$$

$E>17 \mathrm{kcal}$, and the reaction is not observed up to $400^{\circ} \mathrm{C}[36]$.

For $\mathrm{C}_{2} \mathrm{~F}_{4}$ [38] and $\mathrm{C}_{6} \mathrm{H}_{5} \mathrm{~F}$ [39] reacting with $\mathrm{H}$ atoms, the evidence is for an efficient addition rather than abstraction.
In summary, it therefore seems unlikely that fluorine will be abstracted from either $\mathrm{C}_{6} \mathrm{~F}_{6}$ or $\mathrm{C}_{7} \mathrm{~F}_{16}$, except perhaps by "hot" atoms or radicals. Thus, there remains a radical mechanism with dissociation, addition, and recombination steps, yielding a polymer largely nonaromatic. The very low yield of $\mathrm{SiF}_{4}$ requires that $\mathrm{C}_{6} \mathrm{~F}_{6}$ should be a very efficient trap for $\mathrm{F}$ atoms. If the $\mathrm{F}$ atoms are formed in an efficient cage of $\mathrm{C}_{6} \mathrm{~F}_{6}$ molecules, reactions (7) and (10) can predominate over reaction (13)

$$
\mathrm{F} \cdot+\mathrm{F} \cdot \longrightarrow \mathrm{F}_{2}
$$

without requiring any great inequality of rate constants.

Gordon and others $[17,40]$ have written a mechanism for $\mathrm{C}_{6} \mathrm{H}_{6}$ radiolysis involving excited states only. The same mechanism can be written for $\mathrm{C}_{6} \mathrm{~F}_{6}$ :

$$
\begin{gathered}
\mathrm{C}_{6} \mathrm{~F}_{6} \longrightarrow \mathrm{C}_{6} \mathrm{~F}_{6}{ }^{*}, \\
\mathrm{C}_{6} \mathrm{~F}_{6}{ }^{*}+\mathrm{C}_{6} \mathrm{~F}_{6} \longrightarrow\left(\mathrm{C}_{6} \mathrm{~F}_{6}\right)_{2} .
\end{gathered}
$$

Hydrocarbon analogs of the dimer have been reported. An advantage of the excited-state mechanism is that the nearly complete absence of $\mathrm{SiF}_{4}$ (derived from corrosive fragments) is explained simply when fragments are not formed.

At higher temperatures $\left(218^{\circ} \mathrm{C}\right)$ the argument against the radical mechanism does not apply, as considerably more $\mathrm{SiF}_{4}$ is formed. The actual behavior of $\dot{\mathrm{C}}_{6} \mathrm{~F}_{6}$ at higher temperatures offers some difficulties. The black granular insoluble polymer suggest a highly condensed aromatic ring structure formed by extensive elimination of fluorine, yet the yield of polymer is about the same as that at low temperature, and the $\mathrm{SiF}_{4}$ equals somewhat less than $1 \mathrm{~F}$ atom per $\mathrm{C}_{6} \mathrm{~F}_{6}$ ring (see table 4 ).

\subsection{Hexafluorobenzene and Hydrogen}

Hexafluorobenzene and hydrogen produced more $\mathrm{SiF}_{4}$ (from HF) than hexafluorobenzene, but less than in mixtures with hydrocarbons (see table 5, cf.

\begin{tabular}{|c|c|c|}
\hline & $\mathrm{C}_{6} \mathrm{~F}_{6}$ & $\mathrm{C}_{6} \mathrm{~F}_{6}+\mathrm{H}_{2}$ \\
\hline $\begin{array}{l}4 G\left(\mathrm{SiF}_{4}\right) \\
G\left(\mathrm{CO}_{2}\right) \\
G(\mathrm{CO}) \\
G(\mathrm{polymer}) \mathrm{b}\end{array}$ & $\begin{array}{l}0.045 \\
.004 \\
.0012 \\
2.01\end{array}$ & $\begin{array}{l}0.440 \\
.004 \\
0 \\
2.30\end{array}$ \\
\hline
\end{tabular}
tables 3 and 4 ). The pressure of hydrogen was 34 atm at $-80^{\circ} \mathrm{C}$, corresponding to 0.0223 mole in the sample, and the amount of hexafluorobenzene was 0.0176 mole. Assuming pertinent properties of the $\mathrm{C}_{6} \mathrm{~F}_{6}$ to be the same as those of $\mathrm{C}_{6} \mathrm{H}_{6}$, reasonable estimates for the composition are

$$
\begin{array}{lcc} 
& \text { in vapor phase } & \text { in liquid phase } \\
\mathrm{C}_{6} \mathrm{~F}_{6} & 5.67 \times 10-5 \text { mole } & 0.0176 \text { mole } \\
\mathrm{H}_{2} & 0.223 \text { mole } & .00017 \text { mole }
\end{array}
$$

TABLE 5. Radiation yields from hexafluorobenzene and hydrogen $20^{\circ} C^{\text {a }}$

a Exposure dose $319 \mathrm{Mr}$; hydrogen pressure $34 \mathrm{~atm}$.

b $\mathrm{C}_{6} \mathrm{~F}_{6}$ units. 
The dose was $319 \mathrm{Mr}$. Much of the vapor was in a less intense radiation field. For the calculations in table 5 , it is assumed that all radiation was absorbed by $\mathrm{C}_{6} \mathrm{~F}_{6}$ as liquid.

The value of $G\left(\mathrm{SiF}_{4}\right)$ is 0.11 as against 0.01 for pure $\mathrm{C}_{6} \mathrm{~F}_{6}$ and 0.33 for a mixture of $\mathrm{C}_{6} \mathrm{~F}_{6}$ and $\mathrm{C}_{6} \mathrm{H}_{6}$.

Conceivable steps producing the HF may be:

$$
\begin{gathered}
\mathrm{F} \cdot+\mathrm{H}_{2} \longrightarrow \mathrm{HF}+\mathrm{H} \cdot, \\
\mathrm{C}_{6} \mathrm{~F}_{5} \cdot+\mathrm{H}_{2} \longrightarrow \mathrm{C}_{6} \mathrm{~F}_{6} \mathrm{H}+\mathrm{H} \cdot, \\
\mathrm{C}_{6} \mathrm{~F}_{7} \cdot+\mathrm{H}_{2} \longrightarrow \mathrm{C}_{6} \mathrm{~F}_{7} \mathrm{H}+\mathrm{H} \cdot, \\
\mathrm{C}_{6} \mathrm{~F}_{7} \cdot+\mathrm{H}_{2} \longrightarrow \mathrm{C}_{6} \mathrm{~F}_{6}+\mathrm{HF}+\mathrm{H} \cdot, \\
\mathrm{C}_{6} \mathrm{~F}_{6} *+\mathrm{H}_{2} \longrightarrow \mathrm{H}_{2} *+\mathrm{C}_{6} \mathrm{~F}_{6}, \\
\searrow 2 \mathrm{H} \cdot \\
\mathrm{C}_{6} \mathrm{~F}_{6} *+\mathrm{H}_{2} \longrightarrow \mathrm{HF}+\mathrm{H} \cdot+\mathrm{C}_{6} \mathrm{~F}_{5} .
\end{gathered}
$$

These reactions must compete with addition reaction (8) and must be roughly comparable with reactions for $\mathrm{HF}$ production in hydrocarbon mixtures, e.g.,

$$
\mathrm{F} \cdot+\mathrm{C}_{6} \mathrm{H}_{6} \longrightarrow \mathrm{HF}+\mathrm{C}_{6} \mathrm{H}_{5} \text {. }
$$

Any $\mathrm{H}$ atoms produced in reactions (16) to may react by addition or abstraction:

$$
\begin{aligned}
& \mathrm{H} \cdot+\mathrm{C}_{6} \mathrm{~F}_{6} \longrightarrow \mathrm{C}_{6} \mathrm{~F}_{6} \mathrm{H} \cdot, \\
& \mathrm{H} \cdot+\mathrm{C}_{6} \mathrm{~F}_{6} \longrightarrow \mathrm{C}_{6} \mathrm{~F}_{5}+\mathrm{HF} .
\end{aligned}
$$

The radiation received in the vapor is relatively unimportant, estimated at $16 \times 10^{20} \mathrm{ev}$ as compared with $554 \times 10^{20} \mathrm{ev}$ in the liquid. In the liquid, the $\mathrm{H}_{2} / \mathrm{C}_{6} \mathrm{~F}_{6}$ mole ratio is about 0.01 , as against much higher ratios in the mixtures with $\mathrm{C}_{6} \mathrm{H}_{6}$ and $\mathrm{C}_{6} \mathrm{H}_{12}$. For comparable HF production in the two cases this would require that $k_{16}$ be considerably greater than $k_{22}$. For reactions (16) and (22) the activation energies may be near $6 \mathrm{kcal} / \mathrm{mole}$ or less. Somewhat analogous reactions with chlorine are:

$$
\begin{gathered}
\mathrm{Cl} \cdot+\mathrm{H}_{2} \longrightarrow \mathrm{HCl}+\mathrm{H} \cdot ; E \approx 6 \mathrm{kcal}[41], \\
\mathrm{Cl} \cdot+\mathrm{CH}_{4} \longrightarrow \mathrm{CH}_{3} \cdot+\mathrm{HCl} ; E<8 \mathrm{kcal}[42] .
\end{gathered}
$$

Of the other reactions, (17) should be discounted because of the failure to find $\mathrm{C}_{6} \mathrm{~F}_{5} \mathrm{H}$ experimentally. Activation energies for reactions related to (17) and (18) have been estimated [28]:

$$
\mathrm{CF}_{3} \cdot+\mathrm{RH} \longrightarrow \mathrm{CF}_{3} \mathrm{H}+\mathrm{R} \cdot
$$

For the various hydrocarbons $\mathrm{RH}$ the activation energies of the reaction in kilocalories per mole are $\mathrm{C}_{2} \mathrm{H}_{6}, 7.5 ; \mathrm{C}_{6} \mathrm{H}_{6}, 7.7 ; \mathrm{H}_{2}, 8.8$; and $\mathrm{CH}_{4}, 10.3$. Although the basis of the estimates has been criticized [20], comparable work [23 to 29] is consistent with values somewhere near these. The abstraction reactions are generally expected to be slower than the additions to $\mathrm{C}_{6} \mathrm{~F}_{6}$, as discussed earlier for pure $\mathrm{C}_{6} \mathrm{~F}_{6}$.
The formation of $\mathrm{HF}$ can also be accounted for by excited-state mechanisms such as in reactions (20) and (21); there is, unfortunately, no explicit literature for comparison. The attempt to account for $\mathrm{HF}$ without $\mathrm{C}_{6} \mathrm{~F}_{5} \mathrm{H}$ remains somewhat unconvincing, as reaction (21) could be followed by a combination of $\mathrm{C}_{6} \mathrm{~F}_{5}$ and $\mathrm{H}$.

\subsection{Hexafluorobenzene and Benzene}

The data for these mixtures are shown in tables 2 and 3. For comparison, results on $\mathrm{C}_{6} \mathrm{H}_{6}$ are reproduced from the work of other investigators [17]. The polymer analyses are low by 4.3 to 4.9 percent. Since fluorine analyses tend to be low, it is assumed for calculation that the true fluorine value is that obtained from the difference between $(\mathrm{C}$ plus $\mathrm{H})$ and 100. Some of the deficit may, however, have arisen from oxidation of the polymer prior to analysis, which could have lowered the $\mathrm{C}, \mathrm{F}$, and $\mathrm{H}$, and simultaneously introduced $\mathrm{O}$ and some $\mathrm{H}$. To arrive at $G$ (polymer) values, it was assumed formally that polymer is produced by withdrawing $x$ moles of $\mathrm{C}_{6} \mathrm{~F}_{6}$ and $y$ moles of $\mathrm{C}_{6} \mathrm{H}_{6}$ from the liquid and rejecting $z$ moles of $\mathrm{HF}$. If $\mathrm{H}$ and $\mathrm{F}$ are lost in other forms and unequal amounts, small inconsistencies arise. On the basis proposed, one can calculate yields of each type of unit in the polymer and of $\mathrm{HF}$ lost per unit.

Base moles polymer $=x+y=\frac{\text { moles } \mathrm{C}}{6}=\frac{\% \mathrm{C} \times \text { weight }}{100 \times 6 \times 12}$,

Moles HF lost

$\overline{\text { Base mole polymer }}$

$$
=z=3\left\{\frac{\text { moles } \mathrm{C}-\text { moles } \mathrm{F}-\text { moles } \mathrm{H}}{\text { moles } \mathrm{C}}\right\},
$$

$\frac{\text { Moles } \mathrm{C}_{6} \mathrm{~F}_{6}}{\text { Base mole polymer }}=\frac{x}{x+y}$

$$
=\frac{1}{2}\left\{\frac{\text { moles } \mathrm{C}+\text { moles } \mathrm{F}-\text { moles } \mathrm{H}}{\text { moles } \mathrm{C}}\right\} \text {. }
$$

For all the mixtures, $G$ (polymer) is higher than for either pure component, and $G\left(\mathrm{SiF}_{4}\right)$ is very much larger than in pure $\mathrm{C}_{6} \mathrm{~F}_{6}$ (see fig. 2). The $\mathrm{SiF}_{4}$ was almost certainly formed from $\mathrm{HF}$. The color of the polymer solution became darker with increasing $\mathrm{C}_{6} \mathrm{H}_{6}$ content, and the polymer during frozen benzene evaporation remained stiffer and spongier, never collapsing to a clear glass.

The composition of the polymer remained near $1: 1$ for $\mathrm{C}_{6} \mathrm{H}_{6} / \mathrm{C}_{6} \mathrm{~F}_{6}$, even for wide variations in feed ratio (table 2, fig. 3). At increasing $\mathrm{C}_{6} \mathrm{H}_{6}$ feed content, the $\mathrm{H} / \mathrm{C}$ and $\mathrm{F} / \mathrm{C}$ ratios of polymer gradually declined, reflecting the increased removal of $H$ and $\mathrm{F}$ mentioned in connection with the $\mathrm{SiF}_{4}$ yields. As with the pure $\mathrm{C}_{6} \mathrm{~F}_{6}$, the mixture did not show any $\mathrm{CF}_{4}$ or $\mathrm{C}_{2} \mathrm{~F}_{2}$, and only the mixture with the high $\mathrm{C}_{6} \mathrm{H}_{6}$ content, 0.886 mole fraction, showed $\mathrm{CH}_{4}$ or 


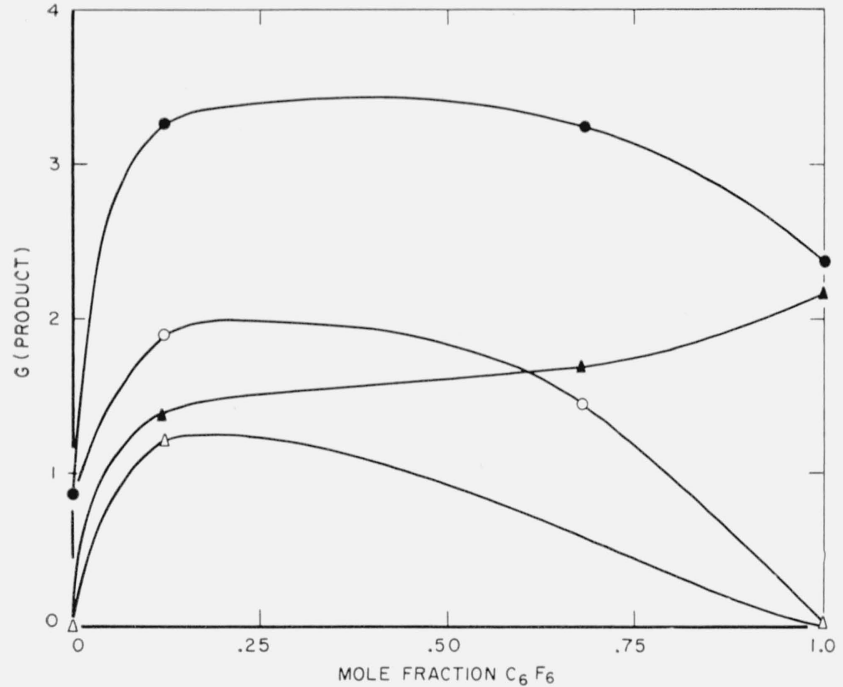

Figure 2. Radiation yields from $\mathrm{C}_{6} \mathrm{~F}_{6}+\mathrm{C}_{6} \mathrm{H}_{6}$.

$G$ (polymer, total), $\bigcirc, G$ (polymer $\mathrm{C}_{6} \mathrm{H}_{6}$ units), $\boldsymbol{\Delta}, G$ (polymer $\mathrm{C}_{6} \mathrm{~F}_{6}$ units), $4 G\left(\mathrm{SiF}_{4}\right)$.

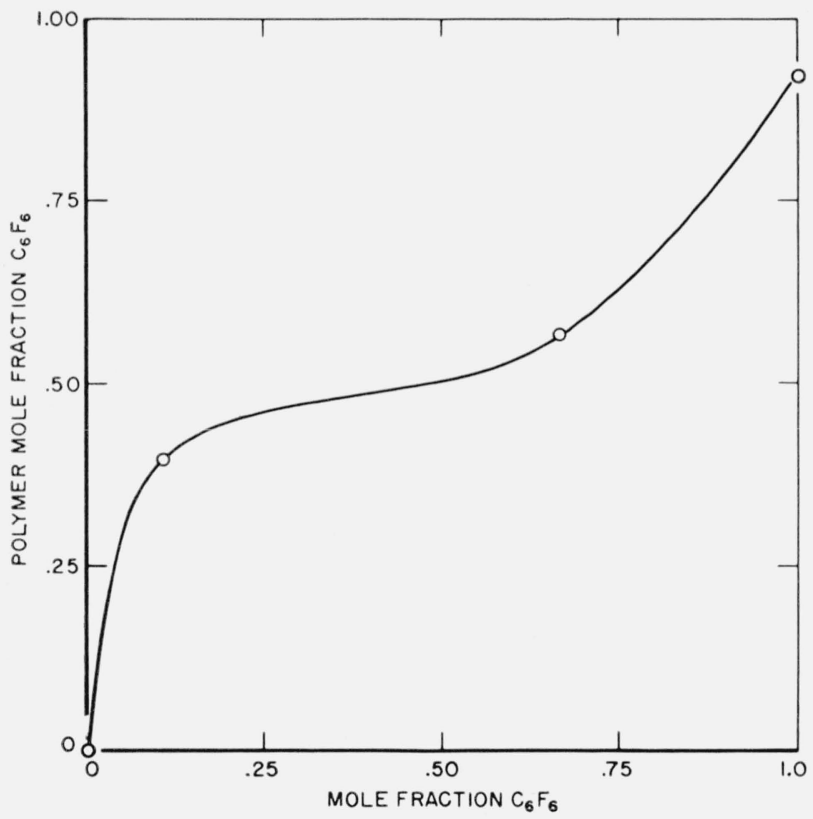

Figure 3. Composition of polymer from $\mathrm{C}_{6} \mathrm{~F}_{6}+\mathrm{C}_{6} \mathrm{H}_{6}$.

$\mathrm{C}_{2} \mathrm{H}_{2}$. Surprisingly, neither $\mathrm{C}_{6} \mathrm{~F}_{5} \mathrm{H}$ nor $\mathrm{C}_{6} \mathrm{H}_{5} \mathrm{~F}$ was found.

The behavior of polymer composition is reminiscent of vinyl copolymerization with a strong alternating tendency. By analogy, a mechanism can be written in which large "crossed" propagation rate constants are responsible for the composition, i.e., where $\mathrm{k}_{29}, \mathrm{k}_{31}>\mathrm{k}_{28}, \mathrm{k}_{30}$.

$$
\begin{aligned}
& m \mathrm{C}_{6} \mathrm{~F}_{6} \cdot+\mathrm{C}_{6} \mathrm{~F}_{6} \stackrel{\mathrm{k}_{28}}{\longrightarrow} \mathrm{C}_{6} \mathrm{~F}_{6}-\mathrm{C}_{6} \mathrm{~F}_{6} \cdot, \\
& \sim \mathrm{C}_{6} \mathrm{~F}_{6} \cdot+\mathrm{C}_{6} \mathrm{H}_{6} \stackrel{\mathrm{k}_{29}}{\longrightarrow} \mathrm{C}_{6} \mathrm{~F}_{6}-\mathrm{C}_{6} \mathrm{H}_{6},
\end{aligned}
$$

$$
\begin{aligned}
& \sim \sim \mathrm{C}_{6} \mathrm{H}_{6} \cdot+\mathrm{C}_{6} \mathrm{H}_{6} \stackrel{\mathrm{k}_{30}}{\longrightarrow} \mathrm{C}_{6} \mathrm{H}_{6}-\mathrm{C}_{6} \mathrm{H}_{6} \cdot \\
& \sim \sim \mathrm{C}_{6} \mathrm{H}_{6} \cdot+\mathrm{C}_{6} \mathrm{~F}_{6} \stackrel{\mathrm{k}_{31}}{\longrightarrow} \mathrm{C}_{6} \mathrm{H}_{6}-\mathrm{C}_{6} \mathrm{~F}_{6} \cdot .
\end{aligned}
$$

Polarity differences often favor addition of unlike units. In partial support, Szware [21] finds the methyl affinities of $\mathrm{C}_{6} \mathrm{~F}_{6}$ and $\mathrm{C}_{2} \mathrm{~F}_{4}$ to be 14 and 10 times greater than the methyl affinities of $\mathrm{C}_{6} \mathrm{H}_{6}$ and $\mathrm{C}_{2} \mathrm{H}_{4}$. The corresponding $\mathrm{CF}_{3}$. affinities do not seem to be known. For these low-molecular weight polymers, favorable crossed terminations could also influence the polymer composition.

There are several possible mechanisms involving excited states. Formally, a "crossed" generation of excited molecules could be favored by an energy transfer mechanism [43]. Against this concept is the fact that the overall formation of polymer is nearly independent of changing composition. It has also been pointed out in criticism that a svmmetrical mutual energy transfer should not occur very generally [40]. Thus, an initial formation of triplet excited states or radicals of the two species in equivalent amounts by mutual transfer of excitation is unlikely. However, the chemical reactivity of triplet excited states may depend on some of the same considerations which apply to free radicals, among which polarity differences are included.

As in the other cases, a decision between the triplet state and radical mechanism is difficult. The obvious qualitative difference is that molecules are dissociated into fragments when forming radicals but not when forming excited states. The presence or absence of fragments is thus one criterion for distinction. Aside from this, it may be necessary to depend upon highly detailed knowledge of the two types of intermediates. Here, the formation of $\mathrm{HF}$ is weak evidence for the presence of some free radicals, while the absence of $\mathrm{C}_{6} \mathrm{H}_{5} \mathrm{~F}$ and $\mathrm{C}_{6} \mathrm{~F}_{5} \mathrm{H}$ is evidence against dissociation. A possible nonradical source of $\mathrm{HF}$ is from the reaction of excited molecules with other excited or ground-state molecules:

$$
\mathrm{C}_{6} \mathrm{H}_{6} *+\mathrm{C}_{6} \mathrm{~F}_{6} \longrightarrow \mathrm{C}_{6} \mathrm{H}_{5}-\mathrm{C}_{6} \mathrm{~F}_{5}+\mathrm{HF} .
$$

At low conversions, there are many more $\mathrm{C}_{6}$ molecules than any other species. The fact that the polymer formed is mainly higher than $\mathrm{C}_{12}$ indicates that the $\mathrm{C}_{12}$ species once formed must retain chemical activity. A radical-addition mechanism allows this to occur in a self-evident way:

$$
\mathrm{C}_{6} \mathrm{H}_{5} \cdot+\mathrm{C}_{6} \mathrm{~F}_{6} \longrightarrow \mathrm{C}_{6} \mathrm{H}_{5}-\mathrm{C}_{6} \mathrm{~F}_{6} .
$$

In a pure triplet-state mechanism, it is not evident that the $\mathrm{C}_{12}$ species would remain in an excited state with a long lifetime. Possibly excited $\mathrm{C}_{6}$ could transfer excitation preferentially to ground-state $\mathrm{C}_{12}$ molecules. Both the relative absence of fragments and the growth of larger species could be explained if excited molecules initially combine to form a biradical which subsequently grows by ordinary radical addition. 
The high $G(\mathrm{HF})$ in mixtures could be formally accounted for by a Bagdassarian [43] or Magat [40] excitation mechanism. An atom and radical mechanism can account for this feature with emphasis on the steps:

$$
\begin{aligned}
& \mathrm{C}_{6} \mathrm{~F}_{6} \longrightarrow \mathrm{C}_{6} \mathrm{~F}_{5} \cdot+\mathrm{F} \cdot \\
& \mathrm{F} \cdot+\mathrm{C}_{6} \mathrm{H}_{6} \longrightarrow \mathrm{C}_{6} \mathrm{H}_{5} \cdot+\mathrm{HF}, \\
& \mathrm{F} \cdot+\mathrm{C}_{6} \mathrm{H}_{6} \longrightarrow \mathrm{C}_{6} \mathrm{H}_{6} \mathrm{~F} \cdot, \\
& \mathrm{F} \cdot+\mathrm{C}_{6} \mathrm{~F}_{6} \longrightarrow \mathrm{C}_{6} \mathrm{~F}_{7} \cdot
\end{aligned}
$$

Here $\mathrm{k}_{22}<\mathrm{k}_{7}<\mathrm{k}_{34}$, but all are of substantial magnitude. To illustrate, a calculation with $\mathrm{k}_{7}=0.1 \mathrm{k}_{34}$, $\mathrm{k}_{22}=0.05 \mathrm{k}_{7}$ predicts a rather flat maximum production of $\mathrm{HF}$ near 0.7 mole fraction $\mathrm{C}_{6} \mathrm{~F}_{6}$.

The data for the mixtures of $\mathrm{C}_{6} \mathrm{~F}_{6}$ and $\mathrm{C}_{6} \mathrm{H}_{6}$ at $218^{\circ} \mathrm{C}$ are very rough because of the small sample size and difficulties of manipulation (see table 4). As with pure $\mathrm{C}_{6} \mathrm{~F}_{6}$ at this temperature, the polymer was insoluble and dark. The $G$ values for both polymer and volatile products seem to vary linearly with composition.

It is not surprising that $G\left(\mathrm{SiF}_{4}\right)$ from $\mathrm{C}_{6} \mathrm{~F}_{6}$ should be higher at high temperature (compare tables 3 and 4$)$, but it is difficult to understand why $G\left(\mathrm{SiF}_{4}\right)$ from the mixtures is less than at room temperature. The polymer from the mixtures resembles that from $\mathrm{C}_{6} \mathrm{~F}_{6}$ at this temperature, and is presumably rich in condensed ring structures or conjugated unsaturation, the formation of which requires elimination of $\mathrm{F}_{2}$ or HF. Thus, the $G\left(\mathrm{SiF}_{4}\right)$ suggests no change from mixtures at $20^{\circ} \mathrm{C}$, whlle the insolubility and color suggest more HF elimination. The dark color of the polymer from mixtures does suggest some conjugated unsaturation even at $20^{\circ} \mathrm{C}$. The principal remaining anomaly may then be the relatively high $G\left(\mathrm{SiF}_{4}\right)$ from pure $\mathrm{C}_{6} \mathrm{~F}_{6}$ at $218^{\circ} \mathrm{C}$. This could be attributed to union of $\mathrm{F}$ atoms as $\mathrm{F}_{2}$, to more efficient escape from a $\mathrm{C}_{6} \mathrm{~F}_{6}$ cage to the wall, or to the onset of $\mathrm{C}-\mathrm{C}$ cleavage like that which produced $\mathrm{C}_{2} \mathrm{H}_{2}$ from benzene. The $\mathrm{C}_{2} \mathrm{~F}_{2}$ and similar fragments could be reactive with the walls of the apparatus.

\subsection{Hexafluorobenzene and Cyclohexane}

From $\mathrm{C}_{6} \mathrm{~F}_{6}$ and cyclohexane, the principal products were $\mathrm{SiF}_{4}(G=0.322), \mathrm{H}_{2} \quad(G=1.92)$, and polymer $\left(G=3\right.$ to 5 ) (see table 6 ). The $G$ value for the $\mathrm{SiF}_{4}$

TABLE 6. Radiation yields from hexafluorobenzene and cyclohexane at $20^{\circ} \mathrm{C}^{\mathrm{a}}$

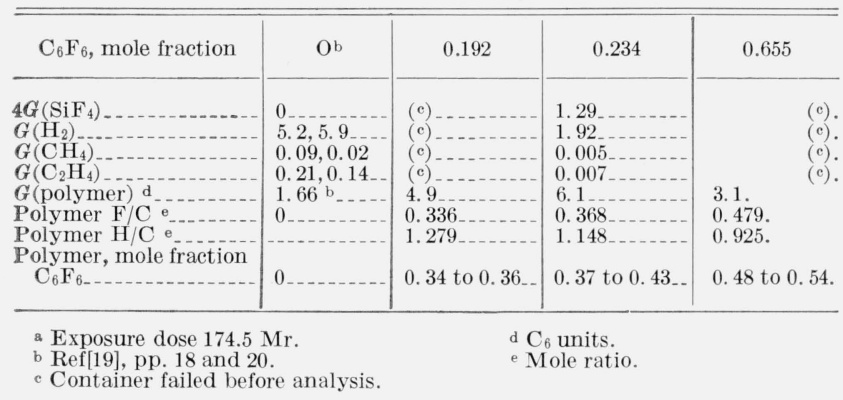

is not very different from that of $\mathrm{C}_{6} \mathrm{~F}_{6}$ and benzene. The polymer composition can be discussed by an extension of the method used for $\mathrm{C}_{6} \mathrm{~F}_{6}$ and $\mathrm{C}_{6} \dot{\mathrm{H}}_{6}$, if $\mathrm{C}-\mathrm{C}$ chain scission products can be neglected. Let each $\mathrm{C}_{6}$ unit of polymer be build from $f$ moles of $\mathrm{C}_{6} \mathrm{~F}_{6}$ and $(1-f)$ moles of $\mathrm{C}_{6} \mathrm{H}_{12}$, rejecting $i$ atoms of $\mathrm{F}$ and $j$ atoms of $\mathrm{H}$. Then

$$
\begin{aligned}
& f=\frac{\mathrm{F}}{\mathrm{C}}+\frac{i}{6}, \\
& f \geq \frac{\mathrm{F}}{\mathrm{C}} \\
& f=1-\frac{1}{2} \frac{\mathrm{H}}{\mathrm{C}}-\frac{j}{12}, \\
& f \leq 1-\frac{1}{2} \frac{\mathrm{H}}{\mathrm{C}} .
\end{aligned}
$$

Similar limiting formulas can be constructed for other systems.

The $G$ value for $\mathrm{H}_{2}(1.92)$ plus that derived for $\mathrm{HF}$ (1.29) is a little less than the usual $G\left(\mathrm{H}_{2}\right)$ [44] for cyclohexane multiplied by the electron fraction $(5.5 \times 0.636=3.5)$. This may correspond to a weak protective effect. Of the $\mathrm{H}_{2}$, some may be formed by a molecular mechanism, but the HF should be from an abstraction by either of the following reactions:

$$
\begin{gathered}
\mathrm{F} \cdot+\mathrm{C}_{6} \mathrm{H}_{12} \longrightarrow \mathrm{HF}+\mathrm{C}_{6} \mathrm{H}_{11} \cdot, \\
\mathrm{H} \cdot+\mathrm{C}_{6} \mathrm{~F}_{6} \longrightarrow \mathrm{HF}+\mathrm{C}_{6} \mathrm{~F}_{5} \cdot .
\end{gathered}
$$

As discussed earlier for hexafluorobenzene and hydrogen, the evidence for reaction (24) or any abstraction from $\mathrm{C}_{6} \mathrm{~F}_{6}$ is weak; for example, in the failure to detect $\mathrm{C}_{6} \mathrm{~F}_{5} \mathrm{H}$ here. For the same reasons, radicals from $\mathrm{C}_{6} \mathrm{H}_{12}$ are not likely to abstract fluorine to form alkyl and cyclohexyl fluorides. The failure to find $\mathrm{RF}$ is not quite conclusive because $\mathrm{C}_{6} \mathrm{H}_{11} \mathrm{~F}$ is rather unstable and smaller scission products of any one kind would be small in amount. On the whole, reaction (35) is preferred as the source of HF. The mechanism of protection may still be either of the sponge type or by addition, as with $\mathrm{C}_{6} \mathrm{H}_{6}$.

\subsection{Perfluoroheptane}

The data of table 7 are rather uncertain because of the large number of possible products and the general ambiguity of mass spectrometer analyses for saturated fluorocarbons. All of these compounds furnish large amounts of fragment ions, especially $\mathrm{CF}_{3}{ }^{+}$, and little parent ion. However, the $G$ values for $\mathrm{SiF}_{4}, \mathrm{CF}_{4}$, and perhaps $\mathrm{C}_{2} \mathrm{~F}_{6}$ are more reliable, as these components were determined at $-80^{\circ}$, where most of the higher fluorocarbons are not volatile enough to interfere. The reported $G$ value may, however, be low because of differential solubility of gases in the liquid at $-80^{\circ}$; by contrast, both $\mathrm{C}_{6} \mathrm{~F}_{6}$ and $\mathrm{C}_{6} \mathrm{H}_{6}$ have high freezing points and at $-80^{\circ}$ would have crystallized, expelling dissolved gases. 
TABLE 7. Radiation yields from hexafluorobenzene and perfluoroheptane at $20^{\circ} \mathrm{C}$ a

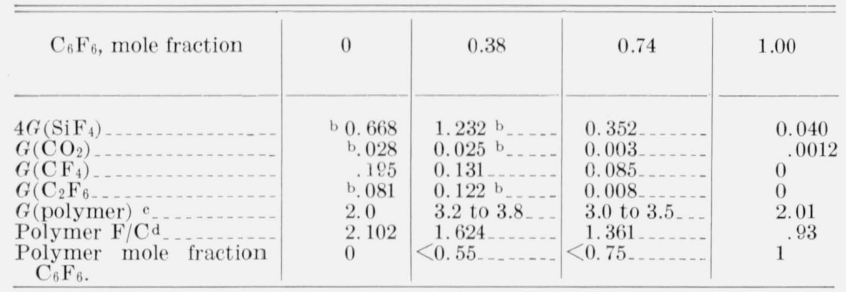

a Exposure dose 330 to $408 \mathrm{Mr}$; dose factor for $\mathrm{C}_{6} \mathrm{~F}_{6}, 0.530 \times 10^{20} \mathrm{ev} / \mathrm{g} \mathrm{Mr}$; for $\mathrm{C}_{7} \mathrm{~F}_{16}, 0.526$.

b May be low because of solubility.

c $\mathrm{As}_{6} \mathrm{C}_{6}$ or $\mathrm{C}_{7}$ units.

d Mole ratio.

The character of the polymer was similar to that reported by other workers. Most boiled in the range $179^{\circ}$ to $250^{\circ}$, and the material was a viscous liquid at $4^{\circ} \mathrm{C}$. For comparison, $n-\mathrm{C}_{12} \mathrm{~F}_{26}$ boils at $175^{\circ}$ and freezes at $42^{\circ}$, and $n-\mathrm{C}_{16} \mathrm{~F}_{34}$ boils at $240^{\circ}$ and freezes at $115^{\circ}$. The failure of the sample to freeze may indicate branched structures, but is not very conclusive in a mixture.

In addition to the data of table 7 , the analyses of liquid in table 8 are of qualitative interest, although both the amounts and identities quoted are subject to large uncertainties of interpretation. Presumably,

TABLE 8. Liquid phase from radiolysis of hexafluorobenzene and perfluoroheptane ${ }^{\mathrm{a}}$

\begin{tabular}{|c|c|c|}
\hline 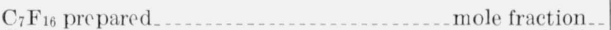 & 1.00 & 0.62 \\
\hline $\mathrm{C}_{i} \mathrm{~F}_{16}$ found & 9.9 & 19.3 \\
\hline $\mathrm{C}_{6} \mathrm{~F}_{6}$ found & 0 & 9.3 \\
\hline $\mathrm{C}_{6} \mathrm{~F}_{14}$ found & 7.0 & 10.2 \\
\hline $\mathrm{C}_{5} \mathrm{~F}_{12} \mathrm{~b}$ found & 6.0 & 5.7 \\
\hline $\mathrm{C}_{3} \mathrm{~F}_{8}$ found .... & 9.0 & 1.5 \\
\hline $\mathrm{C}_{2} \mathrm{~F}_{6}$ found .... & 2.19 & $\sim 0$ \\
\hline
\end{tabular}

a See table 7 , footnote a for radiation conditions. Samples analyzed by mass spectra of vapor at $25^{\circ} \mathrm{C}$.

b Or cyclo- $\mathrm{C}_{5} \mathrm{H}_{10}$.

fractionation effects would weight unduly the lowest boiling components and minimize those above $\mathrm{C}_{7}$. The values of $G\left(\mathrm{CF}_{4}\right)=0.195$ and of $G\left(\mathrm{SiF}_{4}\right)=0.167$ for $\mathrm{C}_{7} \mathrm{~F}_{16}$ are high relative to those for $\mathrm{C}_{6} \mathrm{~F}_{6}$ (table 7 ). The main products are thus $\mathrm{SiF}_{4}$ and higher and lower saturated fluorocarbons. The mass spectrometer finds almost no olefinic molecules. It is possible that more sensitive and reliable indications would be given by infrared or by bromine or permanganate titrations. Stoichiometry requires that the extra fluorine content of the $\mathrm{C}_{1}$ to $\mathrm{C}_{6}$ perfluoroparaffins and the loss to $\mathrm{SiF}_{4}$ be compensated either by equivalent condensation to higher perfluoroparaffins or formation of double bonds. The following reactions are to be considered, where rates can vary with the size of the radicals $R_{i}$ and $R_{j}$ :

$\mathrm{C}-\mathrm{C}$ scission:

$$
\mathrm{C}_{7} \mathrm{~F}_{16} \longrightarrow R_{i} \cdot+R_{7-i} \cdot
$$

$\mathrm{C}-\mathrm{F}$ atom splitting:

$$
\begin{aligned}
& \mathrm{C}_{7} \mathrm{~F}_{16} \longrightarrow \text { sec }-\mathrm{C}_{7} \mathrm{~F}_{15} \cdot+\mathrm{F} \cdot \\
& \mathrm{C}_{7} \mathrm{~F}_{1} \longrightarrow \text { prim }-\mathrm{C}_{7} \mathrm{~F}_{15} \cdot+\mathrm{F} .
\end{aligned}
$$

Recombination:

$$
\begin{gathered}
\mathrm{F} \cdot+\mathrm{F} \cdot \longrightarrow \mathrm{F}_{2}, \\
R_{i} \cdot+\mathrm{F} \cdot \longrightarrow R_{i} \mathrm{~F}, \\
R_{i} \cdot+R_{j} \cdot \longrightarrow R_{i}-R_{j} .
\end{gathered}
$$

Disproportionation:

$$
\begin{aligned}
& R_{i} \cdot+R_{j} \cdot \longrightarrow \mathrm{C}_{i} \mathrm{~F}_{2 i}+\mathrm{C}_{j} \mathrm{~F}_{2 j ! 2}, \\
& \mathrm{~F} \cdot+R_{i} \cdot \longrightarrow \mathrm{C}_{i} \mathrm{~F}_{2 i}+\mathrm{F}_{2} .
\end{aligned}
$$

Radical attack on $\mathrm{F}_{2}$ :

Transfer:

$$
R_{i} \cdot+\mathrm{F}_{2} \longrightarrow R_{i} \mathrm{~F}+\mathrm{F} \cdot
$$

$$
R_{i} \cdot+\mathrm{C}_{7} \mathrm{~F}_{16} \longrightarrow \mathrm{C}_{7} \mathrm{~F}_{15} \cdot+R_{i} \mathrm{~F} .
$$

The transfer reaction (44) is unlikely because of energetics, as previously discussed. Disproportionation (41) and (42) would generate olefinic molecules and so should be unimportant here; moreover, there is convincing experimental evidence against reaction (41) $[23$ to 29]. The remaining reactions, coupled with material balance, all require conservation of total number of molecules, and thus a compensation between product molecules larger and smaller than $\mathrm{C}_{7}$. Larger molecules were found in the distillation residue although not by the mass spectrometer.

To extend the conclusion about conservation of number of molecules from $\mathrm{C}_{7} \mathrm{~F}_{16}$ to high polymers appears inconsistent with the familiar rapid degradation of polytetrafluoroethylene and polychlorotrifluoroethylene. The difficulty could be met by asserting that sufficient oxygen or hydrocarbon material was present in all polymer experiments to combine or undergo $H$ abstraction with the polymer radicals and thus lower the molecular weight; or that the radicals were trapped in the solid matrix and could then undergo various other reactions ordinarily of low probability; or that a relatively very small increase in the number of molecules and double bonds occurs in all cases but is easily noticed only in the polymer. In this connection it has been noticed recently that polytetrafluoroethylene irradiated in vacuo is degraded very much less rapidly than in air [45]. Nevertheless, a thorough search for olefinic molecules in irradiated perfluoroheptane would be desirable.

The set of possible reactions is still too complicated for easy treatment, even when simplified by assumptions such as random splitting and equal reactivity of all radicals. Substantial amounts of all perfluoroparaffins $\mathrm{C}_{1}$ to $\mathrm{C}_{14}$ could be expected. By assuming that all $\mathrm{C}-\mathrm{C}$ and $\mathrm{C}-\mathrm{F}$ bonds split with equal probability, and that all lower radicals disappear only by reaction with $\mathrm{F}$ atoms with equal rate constants, one arrives at an initial fragment distribution:

$$
\begin{aligned}
\mathrm{F}: \operatorname{prim}-\mathrm{C}_{7}: \text { sec }-\mathrm{C}_{7}: \text { all lower alkyl }: \mathrm{CF}_{3} \\
=16: 6: 10: 12: 2
\end{aligned}
$$


and a product distribution in which all lower perfluoroalkanes occur equally and $G\left(\mathrm{CF}_{4}\right)=2 / 46$ times the $G$ value of total initial atoms and radicals. The observed $G\left(\mathrm{CF}_{4}\right)=0.195$ might thus indicate an initial $G$ value for total atoms and radicals as high as 4.5 .

In a liquid phase, the products will be governed by the chances for diffusion before recombination of fragments. The predominant reactions will thus be

$$
\begin{aligned}
& \mathrm{C}_{7} \mathrm{~F}_{16} \longrightarrow \mathrm{C}_{7} \mathrm{~F}_{15} \cdot+\mathrm{F} ., \\
& \mathrm{C}_{7} \mathrm{~F}_{16} \longrightarrow \mathrm{C}_{6} \mathrm{~F}_{13} \cdot+\mathrm{CF}_{3} \cdot(\text { for } i=1) \\
& \mathrm{F} \cdot+\mathrm{F} \cdot \longrightarrow \mathrm{F}_{2}, \\
& \mathrm{~F} \cdot+\mathrm{CF}_{3} \cdot \longrightarrow \mathrm{CF}_{4}(\text { for } i=1), \\
& 2 \mathrm{C}_{7} \mathrm{~F}_{15} \cdot \longrightarrow \mathrm{C}_{14} \mathrm{~F}_{30}[(\text { for } i, j=7), \\
& 2 \mathrm{C}_{6} \mathrm{~F}_{13} \cdot \longrightarrow \mathrm{C}_{12} \mathrm{~F}_{26}(\text { for } i, j=6) .
\end{aligned}
$$

It can be seen that these reactions account for much of the product $\mathrm{SiF}_{4}, \mathrm{CF}_{4}$, and high-boiling residue.

\subsection{Perfluoroheptane and Benzene}

The mixture of perfluoroheptane and benzene was heterogeneous but of considerable qualitative interest. The principal products from irradiation were $\mathrm{SiF}_{4}$ (at a $G$ value about twice that of pure $\mathrm{C}_{7} \mathrm{~F}_{16}$ ), polymer, numerous lower fluorocarbons, and $\mathrm{CF}_{3} \mathrm{H}$ (table 9). The last named compound had a $G$ value of 0.158 by calculation from analyses at $-80^{\circ} \mathrm{C}$; however, the sample, when later warmed to $25^{\circ} \mathrm{C}$, contained large amounts of $\mathrm{CF}_{3} \mathrm{H}$ in the vapor phase, and a rough estimate from the $25^{\circ} \mathrm{C}$ analysis suggested a $G\left(\mathrm{CF}_{3} \mathrm{H}\right)$ in the region of 2 .

TABLE 9. Radiation yields from hydrocarbon-perfluoroheptane mixtures at $20^{\circ} \mathrm{C}$ a

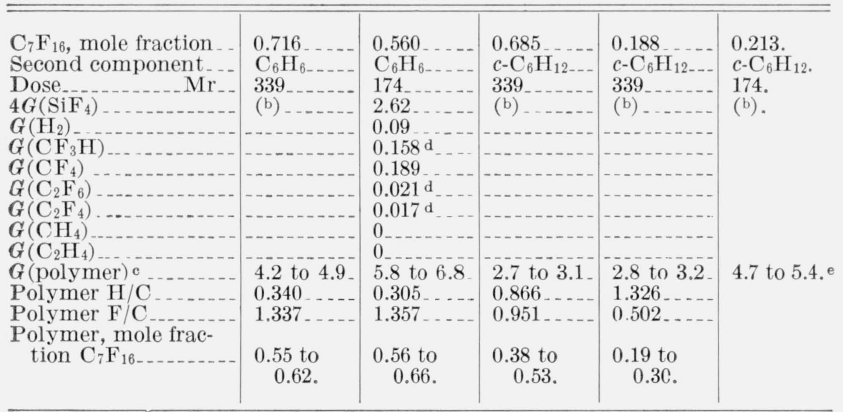

a All samples have two liquid phases.

b Large; failure through glass seal corrosion

c In $\mathrm{C}_{6}$ or $\mathrm{C}_{7}$ units, from weight and carbon analysis.

d May be much too low; large content remains in room temperature analysis.

e From weight, assuming analysis of preceding column.

Inasmuch as $\mathrm{CF}_{3} \mathrm{H}$ boils at $-84^{\circ}$, and $\mathrm{C}_{7} \mathrm{~F}_{16}$, the major component of the mixture, is sometimes liquid at $-80^{\circ}$, it is not unreasonable that most of the $\mathrm{CF}_{3} \mathrm{H}$ present at $-80^{\circ}$ would be held in solution in the $\mathrm{C}_{7} \mathrm{~F}_{16}$. For the same reason, $G$ values for $\mathrm{C}_{2} \mathrm{~F}_{6}$ and $\mathrm{C}_{2} \mathrm{~F}_{4}$ should probably also be much higher. The $\mathrm{CF}_{3} \mathrm{H}$ indicates a clear-cut abstraction reaction from $\mathrm{C}_{6} \mathrm{H}_{6}$ :

$$
\mathrm{CF}_{3} \cdot+\mathrm{C}_{6} \mathrm{H}_{6} \longrightarrow \mathrm{CF}_{3} \mathrm{H}+\mathrm{C}_{6} \mathrm{H}_{5} \text {. }
$$

It is obvious from the presence of $\mathrm{CF}_{4}, \mathrm{C}_{2} \mathrm{~F}_{6}$, etc., that the direct recombinations, $\mathrm{F} \cdot+\mathrm{R} \cdot$ and $\mathrm{R} \cdot+\mathrm{R} \cdot$, still occur to some extent. A comparison with column 1 of table 7 , especially the fairly reliable $\mathrm{CF}_{4}$ values, may indicate essentially no protection of $\mathrm{C}_{7} \mathrm{~F}_{16}$ by either $\mathrm{C}_{6} \mathrm{~F}_{6}$ or $\mathrm{C}_{6} \mathrm{H}_{6}$. The $\mathrm{SiF}_{4}$ values of table 9 indicate a sensitization, but the solubility of $\mathrm{SiF}_{4}$ in $\mathrm{C}_{7} \mathrm{~F}_{16}$ under the conditions of analysis complicates the result, and both $G$ values must be used with caution. Although $\mathrm{C}_{7} \mathrm{~F}_{16}$ in benzene had only moderate $G$ values for products, $\mathrm{C}_{7} \mathrm{~F}_{16}$ in styrene was found to promote polymerization with a rartial electron-fraction $G$ value of $20 \pm 10[46]$. The present $\mathrm{C}_{7} \mathrm{~F}_{16}$ environment should be in some ways similar.

If the high estimate of $G\left(\mathrm{CF}_{3} \mathrm{H}\right)$ of about 2 is correct for $\mathrm{C}_{7} \mathrm{~F}_{16}$ in benzone, it may be consistent with the polymerization $G=20$ for $\mathrm{C}_{7} \mathrm{~F}_{16}$ in styrene, for the various modes of $\mathrm{C}-\mathrm{C}$ and $\mathrm{C}-\mathrm{F}$ scission can form many other radicals as well as the $\mathrm{CF}_{3}$. If the low value in table 8 is more nearly right, then the high results with styrene may require a special energy-transfer effect. In the radiolysis of mixtures of $\mathrm{C}_{6} \mathrm{H}_{6}$ with $\mathrm{C}_{6} \mathrm{H}_{5} \mathrm{CF}_{3}, \mathrm{CF}_{4}$, and chlorofluorocarbons, Feng $[13,14]$ has reported G (radicals) of the order of 1 by the DPPH disappearance method in contrast with the high $G$ (radicals) usually observed for other halocarbons [40]. Although Feng's $\mathrm{CF}_{4}$ effects were observed at unknown high dilution and the difference from pure $\mathrm{C}_{6} \mathrm{H}_{6}$ was close to the experimental error, his $G$ values for $\mathrm{C}_{6} \mathrm{H}_{5} \mathrm{CF}_{3}$ and $\mathrm{CF}_{4}$ in any event were not large, and thus differ from the case of the chlorocarbons. Considering all the evidence, it seems best to suppose that our true $G\left(\mathrm{CF}_{3} \mathrm{H}\right)$ is considerably less than 2 , that $G$ (radicals) is usually low for fluorocarbons, and that the high $G$ (radicals) $=20$ for $\mathrm{C}_{7} \mathrm{~F}_{16}$ in styrene polymerization may be due to special energy transfer effects, valid for styrene but not benzene.

It was further reborted by Feng that the irradiation of $\mathrm{CF}_{4}$ and $\mathrm{C}_{6} \mathrm{H}_{6}$ produced $\mathrm{C}_{6} \mathrm{H}_{5} \mathrm{~F}$ and $\mathrm{C}_{6} \mathrm{H}_{5} \mathrm{CF}_{3}$, detected by infrared, with $G$ values rising to 1.5 $[13,14]$. In the present mixture, $\mathrm{C}_{6} \mathrm{H}_{5} \mathrm{~F}$ was not found, although its formation by combination of $\mathrm{F}+\mathrm{C}_{6} \mathrm{H}_{5}$ is not unreasonable. In the present study, the $\mathrm{C}_{6} \mathrm{H}_{5} \mathrm{~F}$ would have been associated with large proportions of unchanged liquid and perhaps not detected with high sensitivity. The reforted high $G$ value of $\mathrm{C}_{6} \mathrm{H}_{5} \mathrm{~F}$ from so dilute a solution of $\mathrm{CF}_{4}$ is surprising. Possibly other compounds, such as polymer structures formed by addition, could have absorbed at $\mathrm{C}-\mathrm{H}$ and $\mathrm{C}-\mathrm{F}$ frequencies close to those of $\mathrm{C}_{6} \mathrm{H}_{5} \mathrm{CF}_{3}$ and $\mathrm{C}_{6} \mathrm{H}_{5} \mathrm{~F}$, with a very large absorption coefficient.

\subsection{Perfluoroheptane and Cyclohexane}

The mixtures of perfluoroheptane and cyclohexane were heterogeneous. The only data are those upon polymer, table 9, as all containers were broken by corrosion of glass seals, even after rela- 
tively small doses of the order of $70 \mathrm{Mr}$. Presumably the yield of HF was considerably higher than any reported in the tables. Comparison of the polymer yields in columns 4 and 5 suggest that $G$ (polymer) declines with increased dose.

\subsection{Perfluorobenzene and Perfluoroheptane}

With perfluorobenzene and perfluoroheptane (table 7) there appears to be an initial rise in $G\left(\mathrm{C}_{2} \mathrm{~F}_{6}\right)$ as the $\mathrm{C}_{6} \mathrm{~F}_{6}$ content is increased. This is believed to be an artifact due to solubility, as the freezing of $\mathrm{C}_{6} \mathrm{~F}_{6}$ will concentrate the gaseous solutes in the remaining liquid and vapor. The data on $\mathrm{SiF}_{4}$ and $\mathrm{CF}_{4}$ are subject less strongly to the same kind of error, which may seriously underestimate these products where much $\mathrm{C}_{7} \mathrm{~F}_{16}$ is present. There is at least no strong "protective" effect. Since F atoms should be present, it appears that they combine with each other and with aliphatic radicals more readily than they add to $\mathrm{C}_{6} \mathrm{~F}_{6}$. On the other hand, a rapid addition of $\mathrm{F}$ to $\mathrm{C}_{6} \mathrm{~F}_{6}$ is needed in the radical mechanism for $\mathrm{C}_{6} \mathrm{~F}_{6}$ radiolysis to explain the low $\mathrm{SiF}_{4}$ yield. This inconsistency may call into question any purely radical mechanism for the radiolysis of $\mathrm{C}_{6} \mathrm{~F}_{6}$ and favor a triplet-state mechanism there. A similar argument may apply to the radiolysis of $\mathrm{C}_{0} \mathrm{H}_{6}$, which exhibits a protective effect less drastic than might be expected from the radiolysis of the pure component. The very low hydrogen vields from pure $\mathrm{C}_{6} \mathrm{H}_{6}$ may be due mainly to failure to snlit off hydrogen atoms, rather than to rapid reaction with them. The yield of radicals from $\mathrm{C}_{6} \mathrm{H}_{6}$ detected by ordinary methods is somewhat low; $C=0.33-0.89$ by iodine [47] and DPPH disappearance [40]. Possibly it is also of about this same magnitude in mixtures where $\mathrm{C}_{6} \mathrm{H}_{6}$ exhibits a protective effect. The "sponge" mechanism of protection in $\mathrm{C}_{6} \mathrm{H}_{6}$ mixtures has been discussed recently in terms of relations between excited states [40].

The failure of protection in the present mixture suggests that protection, where it occurs, is of the sponge type and not due to extreme reactivity of the aromatic ring with atoms and radicals, and that the characteristics of aromatic radiation chemistry (considerable polymer, very little hydrogen or halogen) depend more upon reactions which proceed via triplet states than upon atom and radical reactions.

\section{Conclusions}

The data presented here show that representative pure liquid fluorocarbons are not especially sensitive toward ionizing radiation. In the paraffinic series, the indicated $\mathrm{C}-\mathrm{C}$ scissions are about equal in $n-\mathrm{C}_{7} \mathrm{~F}_{16}$ and $n-\mathrm{C}_{7} \mathrm{H}_{16}$, as judged by the respective $G\left(\mathrm{CF}_{4}\right)$ and $G\left(\mathrm{CH}_{4}\right)$; and the indicated $\mathrm{C}-\mathrm{F}$ scissions of the fluorocarbon are much less than the $\mathrm{C}-\mathrm{H}$ scissions of the hydrocarbon. The low yield of $\mathrm{C}-\mathrm{F}$ scission products $\left(\mathrm{SiF}_{4}\right)$ may be a cage effect phenomenon. The diffusion away of the hydrogen atom of a $\mathrm{C}-\mathrm{H}$ pair must be an easier process than the corresponding diffusion of a fluorine atom. Results in the gas phase would be interesting for comparison. Even less $\mathrm{C}-\mathrm{F}$ scission than that found here is suggested by the fact that Simons and Taylor [5], irradiating perfluoroaliphatic compounds in allalumiaum containers, found no evidence whatever of corrosive fluorine.

Aside from differences of purity or analytical sensitivity, both sets of observations appear consistent with the existence of a small steady-state concentration of $\mathrm{F}_{2}$, which disappeared in one instance by diffusion to the glass parts of the apparatus and conversion to $\mathrm{SiF}_{4}$, and in the other by attack of fluorocarbon radicals to form lower perfluoroalkanes. Some minimal $\mathrm{C}-\mathrm{F}$ scission seems necessary to account for the considerable amount of $\mathrm{C}_{13}$ and $\mathrm{C}_{14}$ coupling products from $\mathrm{C}_{7} \mathrm{~F}_{16}$. Irradiated polytetrafluoroethylene seems to undergo $\mathrm{C}-\mathrm{F}$ scissions exclusively, according to electron resonance observations [48]. This behavior is again consistent with a cage effect, as $\mathrm{F}$ from a $\mathrm{C}-\mathrm{F}$ scission can diffuse away, while the radical pair from a $\mathrm{C}-\mathrm{C}$ scission is held more rigidly and recombines.

Some of the early indications of fluorocarbon sensitivity were due to the presence of oxygen. Recent studies of the tensile strength of irradiated polytetrafluoroethylene show the loss of tensile is very rapid in the presence of oxygen and hardly perceptible for long periods in its absence [45]. The strong oxygen effect is reminiscent of the degradation of very pure chlorinated compounds exposed to light, air, and moisture. For fluorocarbons under irradiation it may be speculated that the radical recombination rate is somewhat slower than for hydrocarbons, allowing more effective competition by oxygen reactions.

Aromatic fluorocarbons have the same kind of resistance to ionizing radiation as the aromatic hydrocarbons, yielding very little gas and a moderate amount of low polymer. $G$ (polymer) is 2.01 for $\mathrm{C}_{6} \mathrm{~F}_{6}$, as against 0.93 for $\mathrm{C}_{6} \mathrm{H}_{6}$. The polymers from both materials are close to the starting material in elemental analysis. There has been some speculation in the literature concerning the degree of aromatic character present in perhaloaromatic compounds [49]. At least those aspects of aromatic character concerned with radiation resistance seem to remain in the totally fluorinated analog.

Recalling the considerable resistance of polystyrene to radiation, one might predict a similar resistance in polymers containing perfluoroaromatic groups.

Experimentally, poly (2,3,4,5,6-pentafluorostyrene) has a $G$ value for free radicals observed by electron spin resonance, almost as low as polystyrene itself [50], which suggest that the general radiation resistance might be similar. Studies on mechanical and solution properties of large samples would be of interest, as would studies on poly (perfluorostyrene) if it should become available. Presumably, polymers with perfluoroaromatic rings in the main chain, rather than a side chain, would show a better combined resistance to heat and radiation than any styrene derivative. Polyphenyls and perfluoro- 
polyphenylene ethers are the obvious structural possibilities of this kind.

It is not surprising that mixtures of fluorocarbons with hydrocarbons are usually less stable to radiation than the pure components themselves, for the production of hydrogen fluoride is now possible. It is likely that most partially fluorinated compounds would have the same weakness. In spite of the general tendency toward increased sensitivity, hexafluorobenzene appears to repress somewhat the production of hydrogen from cyclohexane. The increased polymer production in mixtures is in most cases a complicated phenomenon, but in the benzenehexafluorobenzene mixtures it exhibits a strong tendency toward equal numbers of benzene and hexafluorobenzene units, as in alternating copolymerization. A likely reason for this behavior is the enhancement of radical or triplet-state reactivities by polarity differences.

At ordinary temperatures, atom and radical mechanisms modified by cage effects seem able to account for the results. Mechanisms involving triplet states, as outlined by other authors for benzene, are perhaps preferable for the perfluoroaromatic systems, especially because of the very slight occurrence of fragmentation. Ionic mechanisms, proposed by Feng for certain hydrocarbon fluorocarbon mixtures, have not been considered here at length because of the fairly satisfactory explanation by other mechanisms and the very short lifetimes to be expected for ions generally in condensed systems.

At higher temperatures $\left(218^{\circ} \mathrm{C}\right)$, the radiation chemistry of hexafluorobenzene is not well understood, but the material retains a fairly good resistance toward inorganic fluoride production and the usual tendency for polymer production. Pure fluorocarbon materials are thus not especially sensitive to radiation, and aromatic fluorocarbons are quite resistant.

\section{References}

[1] M. Hellmann, A. J. Bilbo, and W. J. Pummer, J. Am Chem. Soc. $7 \boldsymbol{7}, 3650$ (1955).

[2] P. Bradt and F. L. Mohler, Anal. Chem. 27, 875 (1955).

[3] F. L. Mohler, V. H. Dibeler, and R. M. Reese, J. Research NBS 49, 343 (1952).

[4] V. H. Dibeler, R. M. Reese, and F. L. Mohler, J. Chem. Physies 26, 304 (1957).

[5] J. H. Simons and E. H. Taylor, J. Phys. Chem. 63, 636 (1959).

[6] D. S. Ballantine, A. Glines, P. Colombo, and P. Manowitz, Further studies of the effect of gamma radiation on vinyl polymer systems, BNL-294 (Mar. 1954).

[7] J. W. Ryan, Modern Plastics 31, 152 (Oct. 1935).

[8] K. Matsumae, M. Watanabe, A. Nishioka, and T. Ichimiga, J. Polvmer Sci. 28, 653 (1958).

[9] J. Byrne, T. W. Costikyan, C. B. Hanford, D. L. Johnson, and W. L. Mann, Ind. Eng. Chem. 45, 2549 (1953).

[10] E. I. du Pont de Nemours and Co., Inc., Brochure on Viton A, p. 11 ca. 1957.

[11] A. Charlesby, Great Britain Atomic Energy Research Establishment Report AERE M/R 978 (1953).

[12] A. Charlesby, Nucleonies 12, No. 6, p. 18 (June 1954).

[13] P. Y. Feng and L. Mamula, J. Chem. Phys. 28, 507 (1958).

[14] P. Y. Feng, The radiation chemistry of fluorinated organic compounds, 2d UN Conference on Atomic Energy (June 1958).
[15] L. Bouby, A. Chapiro, M. Magat, E. Migirdicyan, A. Prevot-Bernas, L. Reinisch, and J. Sebban, Geneva Conference on Peaceful Utilization of Nuclear Energy, Vol. $\boldsymbol{\gamma}$, p. 612 (1955).

[16] W. N. Patrick and M. Burton, J. Am. Chem. Soc. $\boldsymbol{\gamma}$, $2626(1954)$

[17] S. Gordon, A. R. van Dyken, and T. F. Doumani, J. Phys. Chem. 62, 20 (1958).

[18] E. L. Colichman and R. Fish, Pyrolytic and radiolytic decomposition rate studies on Ortho-, meta-, and paraterphenyls, U.S. AEC Report NAA-SR-1287 (1955).

[19] M. Burton, Radiolyse de Liquides Organiques, Chapter 1 in M. Haissinksy (editor) Actions Chimiques et Biologiques des Radiations, 2me Serie, Masson et Cie, Paris (1958).

[20] E. W. R. Steacie, Atomic and Free Radical Reactions, 2 d ed. (Reinhold Publishing Co., New York, N.Y., 1954).

21] M. Szwarc, private communication.

[22] J. Smid and M. Szware, J. Am. Chem. Soc. 79, 1534 (1957).

[23] P. Ayscough and E. W. R. Steacie, Proc. Roy. Soc. A234, 476 (1956).

[24] P. B. Ayscough, J. C. Polanyi, and E. W. R. Steacie, Can. J. Chem. 33, 743 (1955).

[25] P. B. Ayscough, Can. J. Chem. 33, 1566 (1955).

[26] P. B. Ayscough, J. Chem. Phys. 24, 944 (1956).

[27] G. Giacometti and E. W. R. Steacie, Can. J. Chem. 36, 1493 (1958).

[28] G. O. Pritchard, H. O. Pritchard, H. I. Schiff, and A. F. Trotman-Dickenson, Trans. Faraday Soc. 52, 849 (1955).

[29] G. H. Miller, G. O. Pritchard, and E. W. R. Steacie, Z. physik. Chem. 15, 262 (1958).

[30] M. Hellman, E. Peters, W. J. Pummer, and L. A. Wall, J. Am. Chem. Soc. 79, 5654 (1957).

[31] Report of the International Commission on Radiological Units and Measurements (ICRU) 1956; NBS Handbook $\mathbf{6 2}, 10$ to 17,1956 .

[32] D. P. Stevenson and D. O. Schissler, J. Chem. Physies 23, 1353 (1955)

[33] K. H. Geib and P. Harteck, Ber. 66B, 1815 (1933).

[34] W. N. Patrick and M. Burton, J. Phys. Chem. 58, 424 (1954).

[35] P. V. Phung and M. Burton, Radiation Research $\boldsymbol{7 ,} 199$ (1957).

[36] J. Dacey and J. Hodgins, Can. J. Research B28, 173 (1950).

[37] R. A. Sieger and J. G. Calvert, J. Am. Chem. Soc. 76 , $5197(1954)$

[38] P. E. Allen, H. W. Melville, and J. C. Robb, Proc. Roy. Soc. A218, 311 (1953).

[39] E. Boehm and K. Bonhoeffer, Z. physik. Chem. 119, 385 (1926).

[40] M. Magat, L. Bouby, A. Chapiro, and N. Gislon, Z. Elektrochem. 62, 307 (1958).

[41] W. H. Rodebush and W. C. Klingelhoefer, J. Am. Chem Soc. 55, 130 (1930); S. Glasstone, K. J. Laidler, and H. Eyring, Theory of rate processes (McGraw-Hill, New York, N.Y., p. 236, 1941).

[42] H. J. Schumacher, Z. Angew. Chem. 53, 501 (1940).

[43] T. S. Nikitina and C. S. Bagdassarian, Rec. Travaux sur la Chimie des Radiations, ec. Sci. URSS, Moscow, p. $183(1955)$

[44] J. P. Manion and M. Burton, J. Phys. Chem. 56, 560 (1952).

[45] L. A. Wall and R. E. Florin, J. Applied Polymer Science 2, $251(1959)$

[46] L. A. Wall and D. W. Brown, to be published.

[47] E. N. Weber, P. F. Forsyth, and R. H. Schuler, Radiation Research 3, 68 (1955).

[48] H. N. Rexroad and Walter Gordy, J. Chem. Phys. 30, 399 (1959).

[49] W. H. Pearlson, in Fluorine Chemistry, 1, 477, ed. J. H. Simons (Academic Press, Inc., New York, N.Y., 1950).

[50] L. A. Wall, R. E. Florin, and D. W. Brown, to be published.

Washington, D.C.

(Paper 64A4-49) 